\title{
EVALUATION OF MECHANICAL PROPERTIES OF BORAX AND GRAPHITE BASED AL-6061 COMPOSITES
}

\author{
Nagesh.D ${ }^{1}$, Manjunath $\mathbf{S} \mathbf{H}^{2}$ \\ ${ }^{1}$ Assistant Professor, Department of Mechanical Engineering, S J C Institute of Technology, Chickballapur, \\ Karnataka, India. \\ ${ }^{2}$ Professor \& Head, Department of Mechanical Engineering, Sapthagiri College of Engineering, Bengaluru, \\ Karnataka, India
}

\begin{abstract}
Aluminium alloys Metal Matrix Composites are readily replacing automobile, industrial, and aerospace components because of their low density, high strength and good structural rigidity. There have been several technical challenges that exist with casting technology. A uniform distribution during the synthesis of these composite reinforcements with the matrix is a most challenging task in casting. The properties of the composites are directly affected by the casting technique. In the present work an attempt has been made to synthesize 6061Al-Graphite-Borax particulate metal matrix composites by liquid metallurgy route (stir casting technique). The addition level of reinforcement is being varied from 3-9 wt \% in step of 3wt\%. Graphite and Boron was the reinforcement used for enhancing the structural rigidity and weight reduction. Micro structural analysis was carried out to the composites developed by taking specimens from central portion of the casting to ensure homogeneous distribution of particles. Micro-hardness, tensile properties and wear properties of the composites were done as per the standards. Micro structural characterization revealed fairly uniform distribution in the matrix. The tensile strength of the composites was found to increase confirming the dispersed graphite in 6061Al alloy contributed in enhancing the tensile strength of the composites. The wear resistance of the 6061Al-Graphite composite was found to be encouraging for the use in various applications.
\end{abstract}

Key Words: Aluminium 6061, Graphite, Borax, Stir Casting

\section{INTRODUCTION}

Aluminium is the most suited material for research in alloys and development in the aerospace applications owing to light weight and high strength characteristics. There have been several developments in the field of aluminium alloys and its composites ${ }^{[1]}$. Introduction of Graphite has reduced the weight of the composites and have been proved to be best replacement for many automotive applications

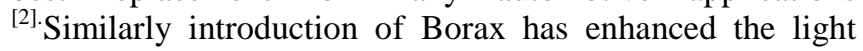
weight characteristics of Aluminium composites and a self lubricating effect when used at various quantities for the researchers ${ }^{[3]}$. In this research an attempt is made to add Graphite and Borax particulate matter into the Aluminium 6061 metal. This study is aimed at synthesis of composites and their characterization studies.

\subsection{Melting Process}

Melting of the composite AL6061 was carried in the form of billets. The composites were melted in a electric furnace. The figure 1 shows the billets being preheated before loading into the furnace.

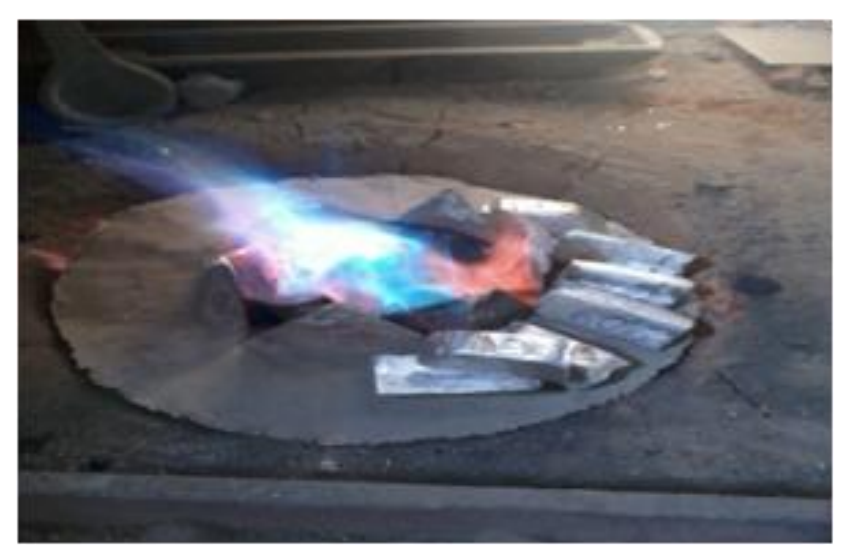

Fig -1: Melted furnace

\subsection{Pouring}

The melted metal was then poured into the metallic moulds for solidification. Pouring of the metal also included mixing of Graphite and Borax at required levels. A suitable percentage of Aluminium Graphite and Borax was selected. It was stated that below $10 \%$ of Graphite ${ }^{[4]}$ was ideal for the mixing and rest of the percentage was Graphite to obtain light weight composites.

The moulds used for pouring is shown in Fig.2 

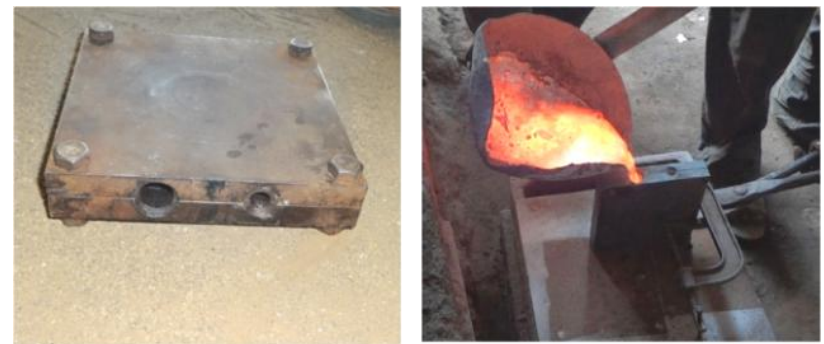

Fig -2: Die used to casting process

\subsection{Cooling}

The moulds were air cooled for 2 hours. The Fig. 3 shows the specimen at various percentages obtained after cooling from the metal moulds. Each specimen was named according to the percentages of the Aluminium used in the moulds.

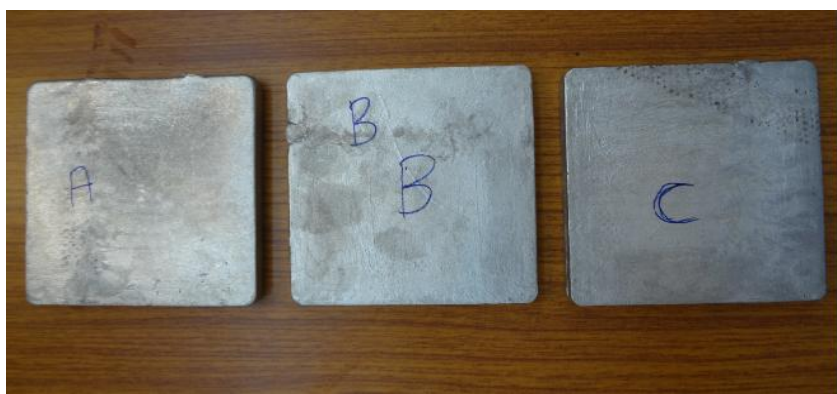

Fig -3: Solidification specimens after removal from die

\subsection{Machining}

The mould components were machined using EDM wire cutting machine as per the specifications as shown in the figure. $4 \& 5$
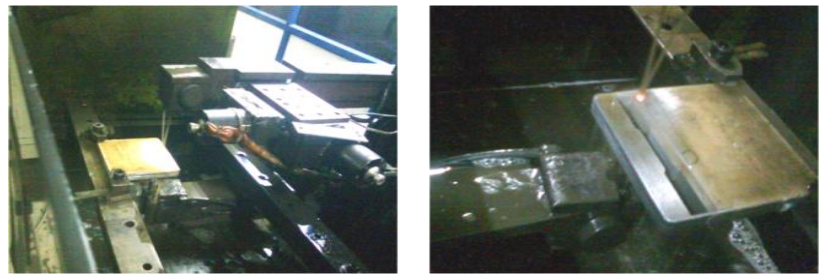

Fig -4: EDM wire cutting machine setup
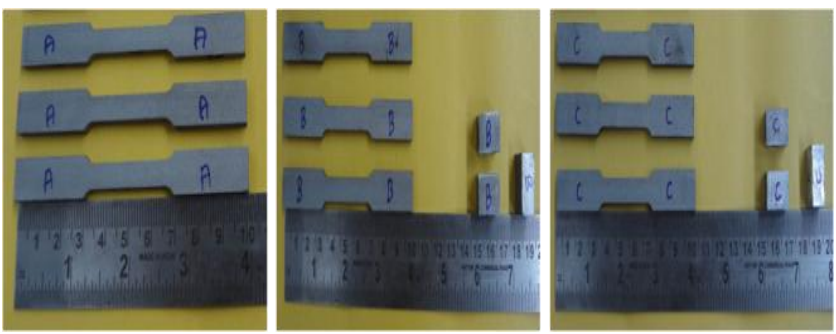

Fig -5: Test specimens for tensile test

\section{EXPERIMENTAL DETAILS}

The Al 6061 composite was subjected to mechanical properties.

\subsection{Hardness Test}

Hardness test was conducted using the Micro Vickers hardness tester at room temperature as per ASTM standard. And results have been tabulated in Table
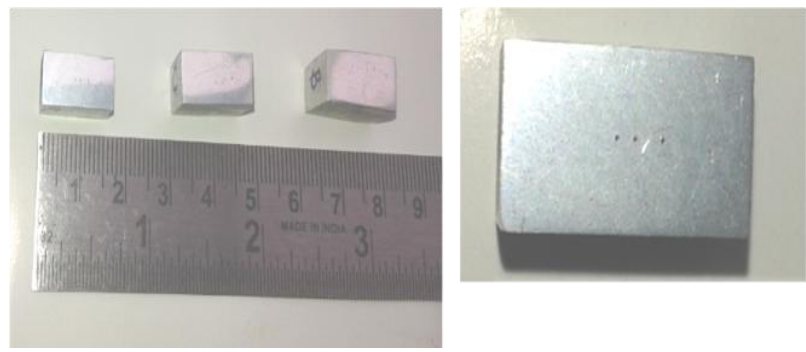

Fig -6: Indentation on the specimen after the hardness test

\subsection{Wear Test}

Specimen for wear test was made as per ASTM G95(Fig.7) Initial tests are carried out in order to ascertain the range of parameters via load, speed and distance. The tribological responses are expected in terms of wear friction co-efficient and specific wear rate.

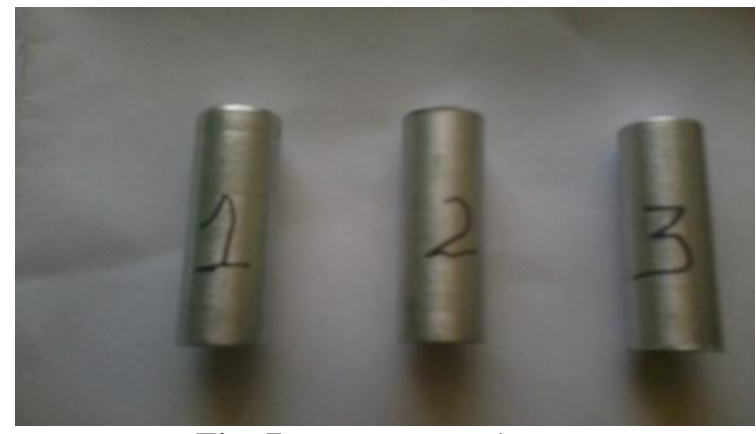

Fig -7: wear test specimen

Pin on disc apparatus was used to study the wear behavior of the material. The specimen is fixed vertically in the pin holder such that the bottom surface of the specimen is in contact with the disc surface. The parameters such as speed, frictional force, time and wear are initially set. After the set time is elapsed the machine stops automatically. The loads applied were $20 \mathrm{~N}, 40 \mathrm{~N}, 60 \mathrm{~N}$. The speed of the disc was 200,400 and $600 \mathrm{rpm}$. Time duration was 10 minutes for each specimen. The distance between the centers of disc to the centre of pin was $40 \mathrm{~mm}$.

\subsection{Tensile Strength}

The tensile test specimen was made as per ASTM E517 standards as shown in the Fig. 8

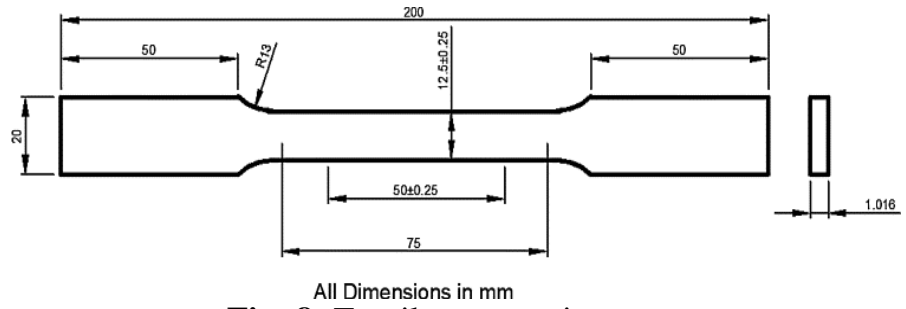

Fig -8: Tensile test specimen 


\section{RESULTS AND DISCUSSIONS}

\subsection{Micro Structure:}

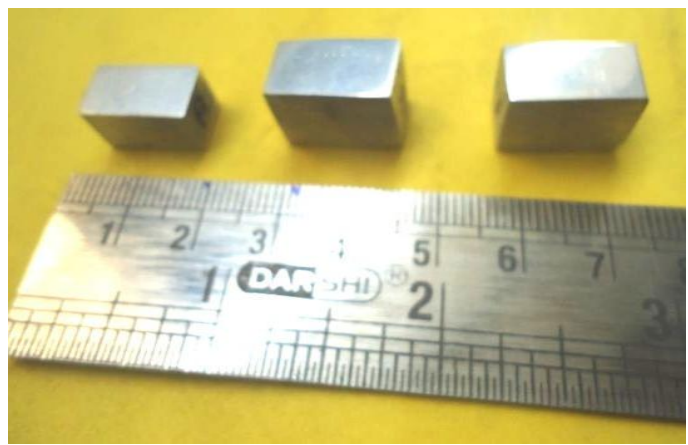

Fig -9: Microstructure Specimen

The specimen used for micro structural study is shown in Fig.9
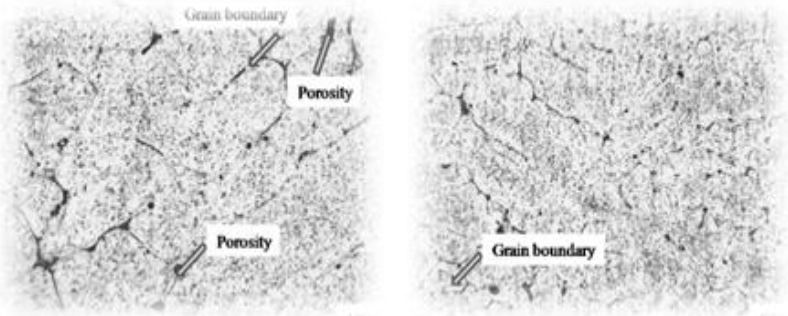

Fig -10 Optical micrographs of MMC's composition A 100$200 \mu(3 \%$ Gr+3\% Borax $)$

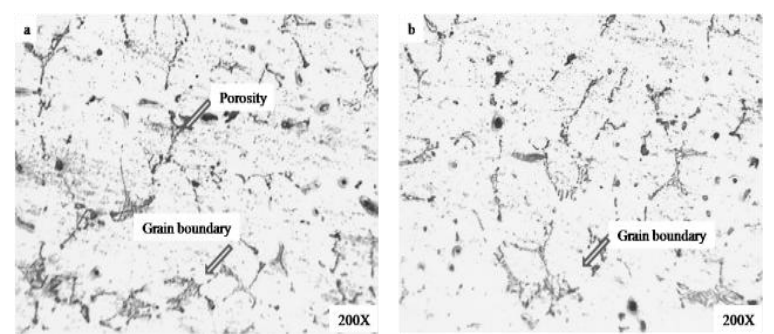

Fig -11: Optical micrographs of MMC's composition B $200 \mu(6 \%$ Gr+6\% Borax $)$
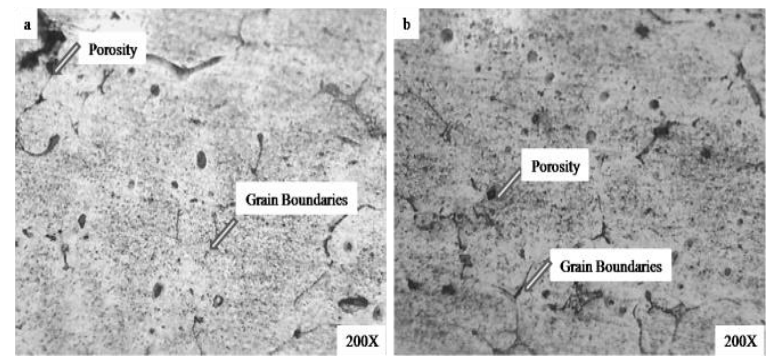

Fig -12: Optical micrographs of MMC's composition C $200 \mu(9 \%$ Gr+9\% Borax)

The optical images of the composite with different ratio of graphite and borax presented in Figs $10,11 \& 12$, shows how the particulates and matrix material compacted with each other. Metallographic examinations reveal that the presence of reinforcement particles was observed on the matrix phase as dark spots, the number of dark areas increases in the matrix phases as the addition of particles increases from $3 \%$ to $9 \%$.

\subsection{Scanning electron microscopy (SEM)}

The etched specimens were observed under SEM (Scanning Electron Microscope) revealed the following structure.
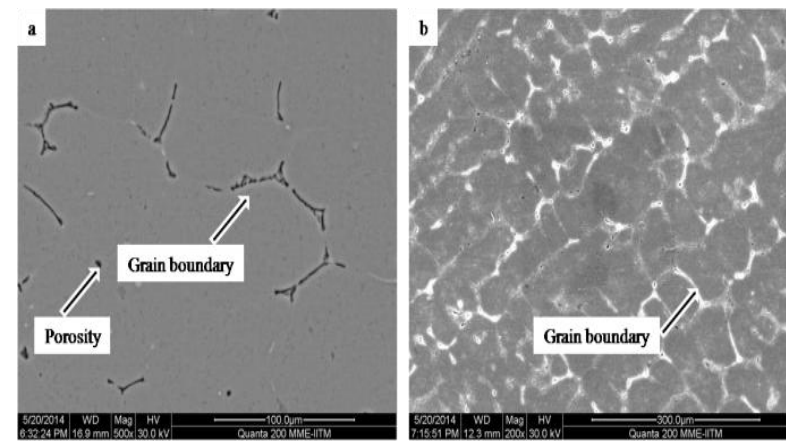

Fig -13: SEM micrographs of MMC's Composition A (3\% Gr+3\% Borax)
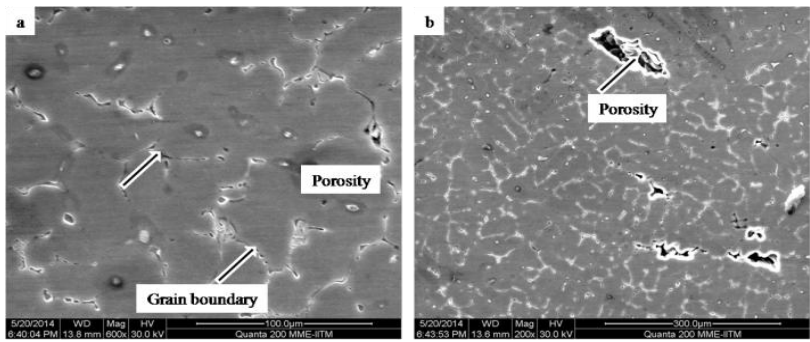

Fig -14: SEM micrographs of MMC's Composition B (6\% Gr+6\% Borax)
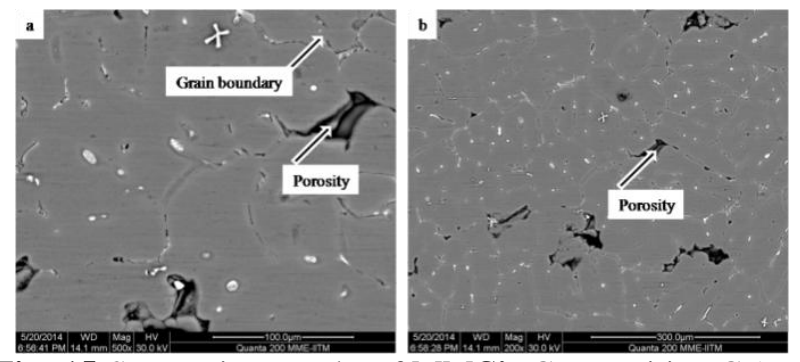

Fig -15:SEM Micrographs of MMC's Composition C (9\% $\mathrm{Gr}+9 \%$ Borax)

The SEM micrographs clearly indicate that Graphite and Borax particulates are dispersed uniformly in $\mathrm{Al}$ matrix even at wt percentage high at $9 \% \mathrm{wt}$ and low at $6 \% \mathrm{wt}$,and $3 \%$ wt.

The microstructure of the Borax, Gr p/6061 Al composites with different particle sizes are shown in micrographs. The particles are tightly packed with a homogeneous spatial distribution in each composite. The distribution of particulate reinforcement is rather uniform; the aluminium matrix is seen as continuous material.

Particulates are seen in between the matrix small sizes with grain boundaries and we can observe addition of reinforcements differ in structure increasing the porosity and mechanical defects and it's are relatively large and oval grains. 


\subsection{EDAX report}

EDAX is a widely used technique to analyze the chemical components in a material under SEM.

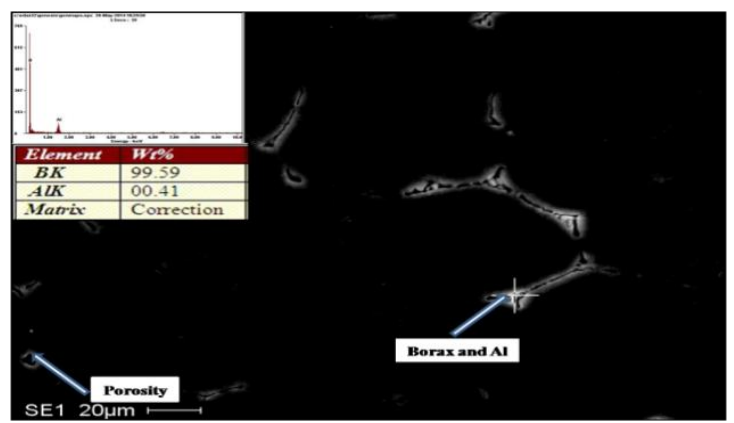

Fig. 16; EDAX result of composition A (3\% Gr+3\% Borax)

X-ray data is processed to obtain the percentage of each measured element present in the individual particles. The SEM-EDAX is routinely used to obtain morphological information of the stone surface and identification of chemical composition. During experimentation careful deep observation indicates a whitish cellular phase in the composition of $\mathrm{Al}$ and \% of $\mathrm{Gr}$, Borax particulates.

EDAX micrographs show the elemental analysis of the Al matrix alloy and \% of particulates. The Figure 16 EDAX report confirms the presence of $\mathrm{Al}$ and Borax, Graphite and the presence of some minor impurities, showing Borax mixed with $\mathrm{Al}$ matrix material.

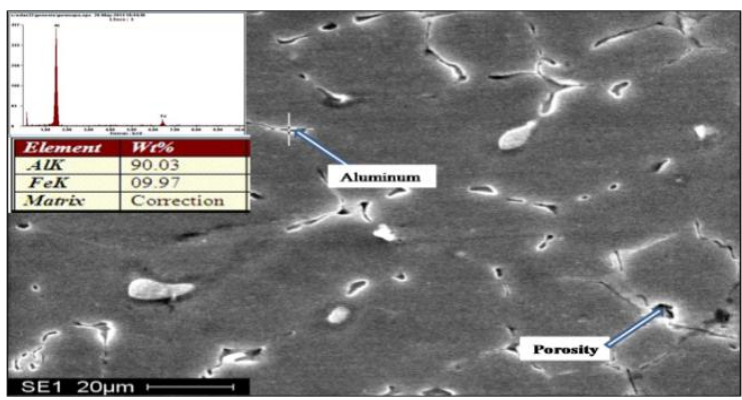

Fig. 17: EDAX result of composition B ( $6 \% \mathrm{Gr}+6 \%$ Borax)

Fig 17 shows the EDAX report of composition B, here the matrix material $\mathrm{Al}$ mixed with impurity alloy of $\mathrm{Fe}$ and Fig 18 shows the EDAX report of composition $\mathrm{C}$, here the particulates are mixed with major alloying elements such as vanadium, chromium and manganese.

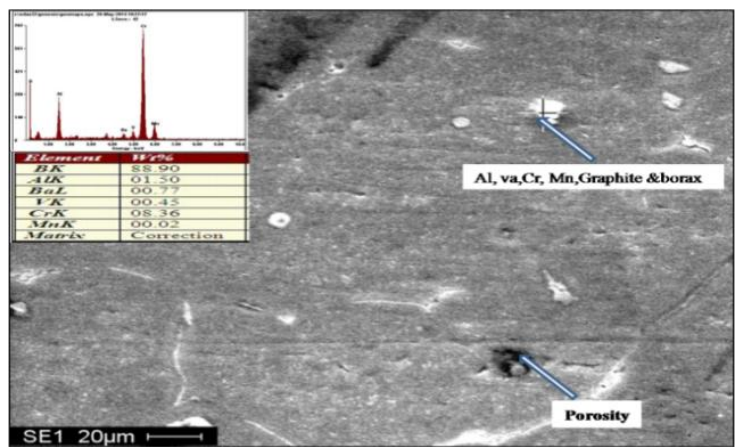

Fig. 18: EDAX result of composition C (9\% Gr+9\% Borax)

\subsection{Hardness test}

Hardness test was conducted using the Micro Vickers Hardness tester at room temperature. it could be seen from the fig .19 that the hardness of the test specimen decreased as the weight percentage of graphite reinforcement increased.

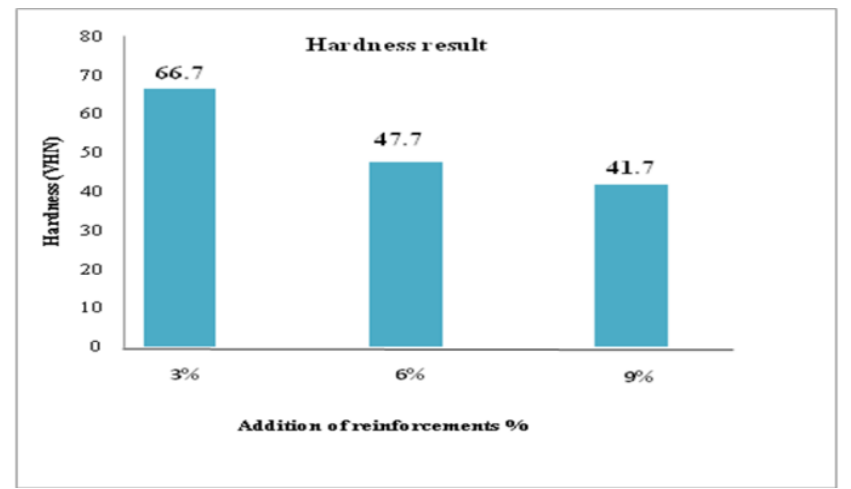

Fig. 19: Graphical representation of Hardness comparison.

\section{5: Density}

Density of the specimens was measured using the water displacement method. The values of density recorded in table1

Table1: Density of composite with varying percentage of reinforcements.

\begin{tabular}{|c|c|c|}
\hline Materials & Theoretical & Experimental \\
\hline $\begin{array}{c}\text { Composition } \\
\text { A }\end{array}$ & $2.72 \mathrm{gm} / \mathrm{cm}^{3}$ & $2.59 \mathrm{gm} / \mathrm{cm}^{3}$ \\
\hline $\begin{array}{c}\text { Composition } \\
\text { B }\end{array}$ & $2.67 \mathrm{gm} / \mathrm{cm}^{3}$ & $2.61 \mathrm{gm} / \mathrm{cm}^{3}$ \\
\hline $\begin{array}{c}\text { Composition } \\
\text { C }\end{array}$ & $2.47 \mathrm{gm} / \mathrm{cm}^{3}$ & $2.62 \mathrm{gm} / \mathrm{cm}^{3}$ \\
\hline
\end{tabular}

From the Fig,20, it is observed that the experimental values are relatively lesser than the theoretical data. This may be due to fabrication and metallurgical factors.

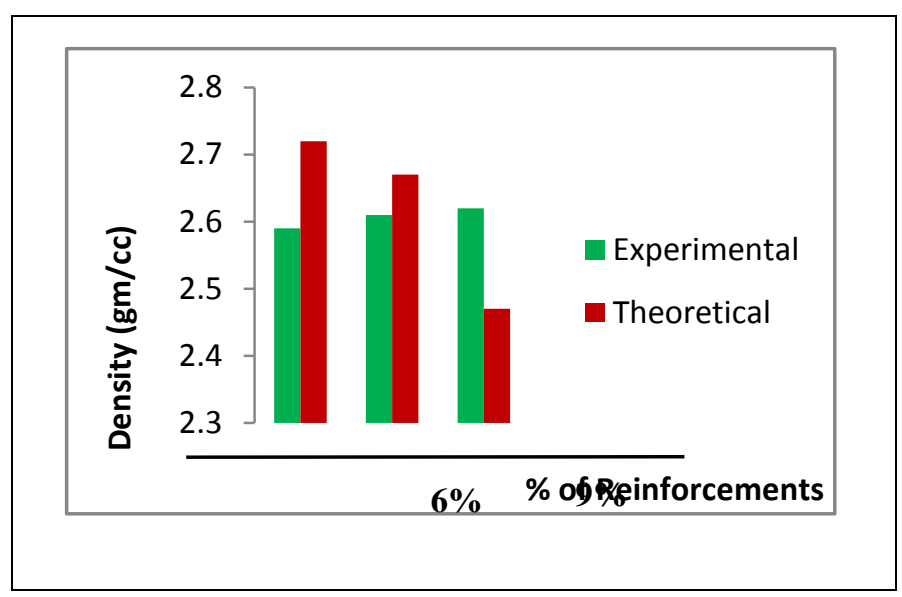

Fig. 20: Comparison of Experimental v/s Theoretical Density. 


\subsection{Tensile Test}

Tension test were conducted on computer-interfaced universal testing machine SR.NO.091101, with a capacity of $100 \mathrm{KN}$. Data acquisition software 'KALPAK' was used for testing, the rate of loading was $1.3 \mathrm{~mm} / \mathrm{min}$.

The tensile test was conducted at room temperature. The experiments are repeated thrice and average readings were computed and presented in table 2 .

Table 2: Tensile strength at varying percentage of reinforcements.

\begin{tabular}{|c|c|c|c|}
\hline $\begin{array}{l}\text { Weight \% of } \\
\text { reinforcement }\end{array}$ & $\begin{array}{l}\text { Sample } \\
\text { number }\end{array}$ & $\begin{array}{l}\text { Tensile } \\
\text { strength } \\
\text { (M Pa) }\end{array}$ & $\begin{array}{l}\text { UTS } \\
\text { (M Pa) }\end{array}$ \\
\hline \multirow{3}{*}{$\begin{array}{c}\text { Composition } \\
\text { A }\end{array}$} & 1 & 119.90 & \multirow{3}{*}{$\begin{array}{c}111.5 \pm 12.4 \\
2\end{array}$} \\
\hline & 2 & 120.52 & \\
\hline & 3 & 93.87 & \\
\hline \multirow{3}{*}{$\begin{array}{c}\text { Composition } \\
\text { B }\end{array}$} & 1 & 101.48 & \multirow{3}{*}{$95.9 \pm 6.83$} \\
\hline & 2 & 99.91 & \\
\hline & 3 & 86.26 & \\
\hline \multirow{3}{*}{$\begin{array}{c}\text { Composition } \\
\mathrm{C}\end{array}$} & 1 & 101.87 & \multirow{3}{*}{$78.5 \pm 16.8$} \\
\hline & 2 & 70.25 & \\
\hline & 3 & 63.33 & \\
\hline
\end{tabular}

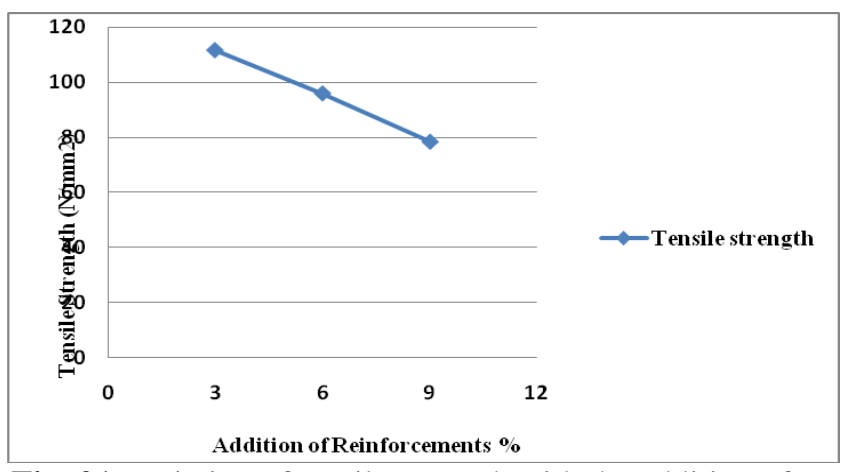

Fig. 21 Variation of tensile strength with the addition of $\%$ reinforcements.

The tensile strength decreases with the addition of reinforcements because the matrix material is varying by composition and increases the addition of reinforcement's cause's mechanical defects.
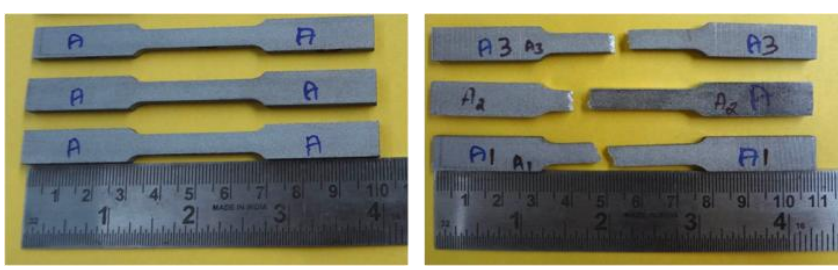

Fig. 22 Tensile test specimens before and after test conducted.

\subsection{Wear Test}

Table 3: wear test under varying load condition.

\begin{tabular}{|c|c|c|c|c|c|}
\hline Specimen & Trail & $\begin{array}{c}\text { Weight } \\
\text { loss in } \\
\text { gm }\end{array}$ & $\begin{array}{l}\text { Load } \\
\text { in kg }\end{array}$ & $\begin{array}{c}\text { Wear } \\
\text { rate } \\
\left(\mathrm{m}^{2} / \mathrm{n}\right) \\
* 10^{-12}\end{array}$ & $\begin{array}{c}\text { Frictional } \\
\text { force } \\
\mathbf{N} * 10^{-5}\end{array}$ \\
\hline \multirow{4}{*}{$\mathbf{A}$} & 1 & 0.008 & 2 & 2.10 & 3.14 \\
\hline & 2 & 0.009 & 3 & 2.40 & 8.08 \\
\hline & 3 & 0.009 & 4 & 3.20 & 19.16 \\
\hline & 4 & 0.01 & 5 & 5.30 & 49.59 \\
\hline \multirow{4}{*}{ B } & 1 & 0.015 & 2 & 3.87 & 5.79 \\
\hline & 2 & 0.017 & 3 & 4.51 & 15.20 \\
\hline & 3 & 0.018 & 4 & 5.684 & 34.02 \\
\hline & 4 & 0.02 & 5 & 7.623 & 71.30 \\
\hline \multirow{4}{*}{$\mathbf{C}$} & 1 & 0.018 & 2 & 5.21 & 7.79 \\
\hline & 2 & 0.023 & 3 & 6.54 & 22.03 \\
\hline & 3 & 0.025 & 4 & 7.816 & 46.77 \\
\hline & 4 & 0.026 & 5 & 9.375 & 95.86 \\
\hline
\end{tabular}

From the above table we see that wear rate of the composite decreases with increase in hardness of material.

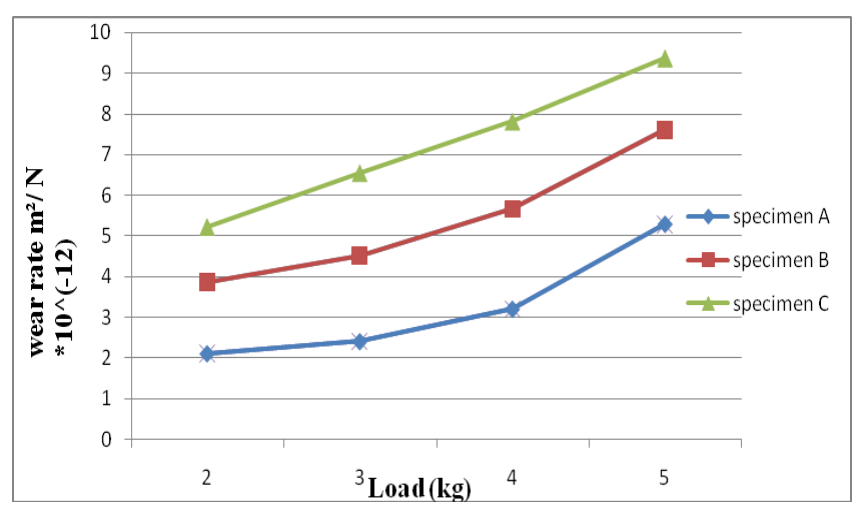

Fig. 23 Comparison of wear rate with load.

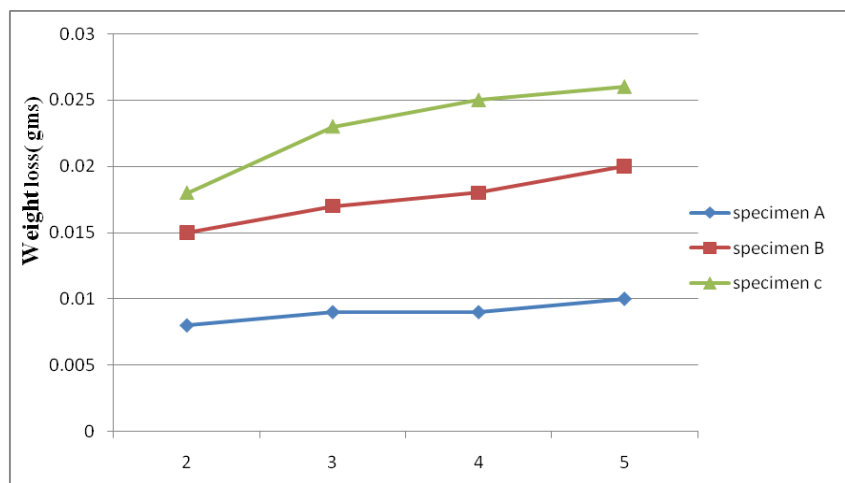

Fig. 24 Comparison of weight loss with load. 


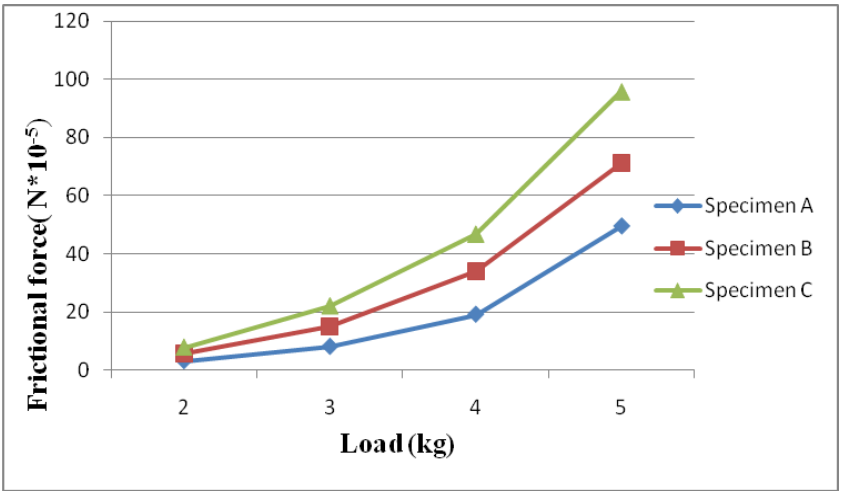

Fig. 25 Comparison of frictional force with load.

considering the wear rate of specimen A for $2 \mathrm{~kg}$ we see that the wear rate is $2.10 * 10^{-12}$ and for $3 \mathrm{~kg}$ it is $2.40 * 10^{-12}$ and for $4 \mathrm{~kg}$ it is $3.20 * 10^{-12}$ and for $5 \mathrm{~kg}$ it is $5.30^{*} 10^{-12}$. We could see that the wear rate has been continuously increased due to increase in load.

If we see the wears rate of the specimen individually like Specimen A, Specimen B, Specimen C it has been increased with increase in addition of particulates with the same percentage.

If we see the wear rate of the specimen are like Specimen A, Specimen B, Specimen C it has been increased with increase in addition of borax and graphite particulates with the same compositions.

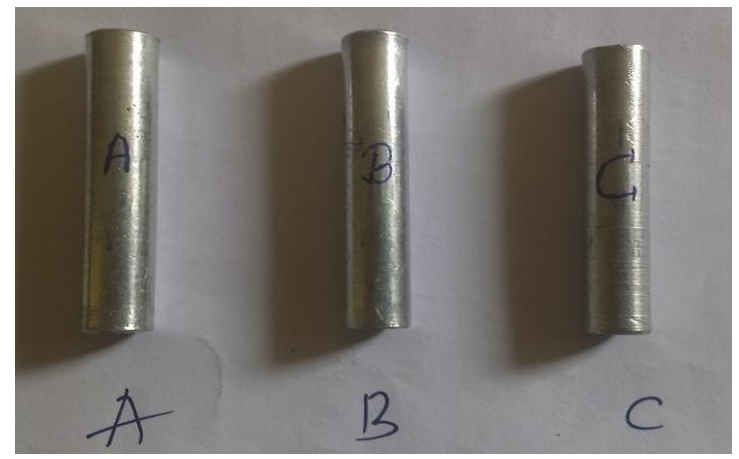

Fig. 26: Wear Test Specimen.

\section{CONCLUSIONS}

In the current study of aluminum based Hybrid metal matrix composites reinforced with Graphite and Boron particles. The following conclusions are drawn from the experimental results.

Mechanical properties such as tensile strength, compression strength and modulus of elasticity decreases and percentage of elongation increases in addition of particulates materials become less stiffer and the resistance afforded by the material against the tensile load decreases.

Because of the presence of graphite and boron particles the ductility starts increasing and drastically increases weight percentage of reinforcement to the base metal percentages varying by compositions.
Wear rate starts decreases with the increase in reinforced particles. It was found that at higher speeds the wear rate relatively lesser for any particular load.

With the increase in addition of reinforcement of both the particles the hardness is decreases because increasing the percentage of graphite and decreasing the base metal percentages, and casting defects.

The experimental densities were found to be lower than theoretical densities due to the presence of porosities in all the composites.

Here the first addition is increases and next addition is slightly decreases because the base metal also varying by percentages and the increasing the reinforcements are causes the mechanical defects like void, porosity like that so, increasing the percentages of reinforcements results decreasing the mechanical properties.

The micro structural studies reveal that the concentration of both particles in the matrix phase increases with the increase in percentage of reinforcements. In a magnification of 200X, the etched surface of the developed hybrid metal matrix composites shows the clear interface between the matrix and reinforcement.

\section{REFERENCES}

[1] Prashant S N, Madev Nagara "Preparation and evaluation of mechanical and wear properties of 6061Al reinforced with Graphite and sic particulate MMC's" Department of Mechanical Engineering, Siddaganga Institute of Technology.

[2] A Ramesh, J. N. Prakash, A. S. Shiva Shankare Gowda and Sonnappa Appaiah "Comparison of the Mechanical Properties of AL6061/Albite and AL6061/Graphite Metal Matrix Composites" Department of Mechanical Engineering, Alpha College of Engineering, Dr. M.G.R Educational and Research Institute, Department of Industrial Engineering and Management, M.S.R.I.T bangalore.

[3] Arun Kumar M. B, R. P. Swamy "Evaluation of mechanical properties of al6061, flyash and e-glass fiber reinforced hybrid metal matrix composites" University BDT College of Engineering, vol. 6, no. 5, may 2011

[4] Manchang Gui, Suk Bong Kang b,"Aluminum hybrid composite coatings containing Sic and graphite Particles by plasma spraying" a National Laboratory of Advanced Composites, Institute of Aeronautical Materials, March 2001.

[5] Arun.L.R, Saddam Hussain. B, Dr. Suneel Kumar N.Kulkarni "Dynamic behaviour of hybrid aluminium6061 metal matrix reinforced with sic and fly ash particulates" InternationalJournal of Innovative Research in Science, Engineering and Technology Vol. 2,Issue 6, Jun 2013

[6] Mahendra Boopathi, K.P. Arulshri and N. Iyandurai "Evaluation of mechanical properties of aluminium alloy 2024 reinforced with silicon carbide and fly ash 
hybrid metal matrix composites" American Journal of Applied Sciences, 10 (3): 219-229, 2013

[7] Ajay Singh, Love Kumar, Mohit Chaudhary, Om Narayan, PallavSharma, Piyush Singh, Bhaskar Chandra Kandpal, Som Ashutosh "Manufacturing of AMMCs using stir casting process and testing its mechanical properties" International Journal of Advanced Engineering Technology E-ISSN 0976-3945

[8] Basavaraju.S, Arasukumar.K, Dr.Chandrashekhar Bendigeri, Dr.C.K.Umesh "Studies on Mechanical Properties and Tribological Characteristics of LM25 Graphite- Silicon Carbide and LM25-Flyash- Silicon Carbide - Hybrid MMC's" International Journal of Innovative Research in Science, Engineering and Technology Vol. 1, Issue 1, November 2012

[9] M.B.Harun, "Effect Of Fly ash Particulate Reinforced On Microstructure, Porosity and Hardness In AL-(SiMg)", AJSTD Vol. 23 Issues 1\&2 pp. 113-122 (2006)

[10] Neelima devi.C, "Mechanical characterization of Aluminium silicon carbide composite". International Journal of Applied Engineering Research, Dindigul, Volume 1, No 4,2001

[11] G.N.Lokesh, " Effect of Hardness, Tensile and Wear Behaviour of Al-4.5wt.\% Cu Alloy/Fly ash/ SiC metal matrix composite". International Journal of Modern Engineering Research(IJMER) Vol.3.Issue.1 JanFeb.2013 pp-381-385 ISSN: 2249-6645.

\section{BIOGRAPHIES}

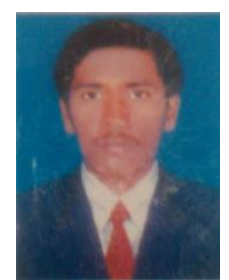

NAGESH D, Graduated in BE (mechanical Engineering) SJCIT, Chickballapur. And M.Tech (manufacturing science and engineering) from PESIT, Bengaluru have three years of teachning experience and also in resesrch field from past 3 years. The area research work is hybrid metal matrix composites.

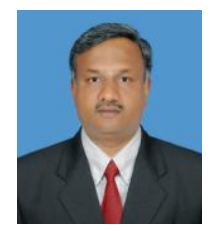

Dr. S.H MANJUNATH Graduated in BE (mechanical Engineering) from BMSCE, Bengaluru, completed $\mathrm{ME}$ and $\mathrm{PhD}$ from UVCE Bangalore and served in different engineering colleges in various capacities and have proven record of accomplishment of valuable service in teaching and research. 